\title{
Article
}

\section{Does Instructor Type Matter? Undergraduate Student Perception of Graduate Teaching Assistants and Professors}

\author{
K. Denise Kendall and Elisabeth E. Schussler
}

\author{
Department of Ecology and Evolutionary Biology, University of Tennessee, Knoxville, TN 37996
}

Submitted October 7, 2011; Revised January 25, 2012; Accepted January 25, 2012

Monitoring Editor: Debra Tomanek

\begin{abstract}
Graduate teaching assistants (GTAs) are used extensively as instructors in higher education, yet their status and authority as teachers may be unclear to undergraduates, to administrators, and even to the GTAs themselves. This study explored undergraduate perception of classroom instruction by GTAs and professors to identify factors unique to each type of instructor versus the type of classes they teach. Data collection was via an online survey composed of subscales from two validated instruments, as well as one open-ended question asking students to compare the same class taught by a professor versus a GTA. Quantitative and qualitative results indicated that some student instructional perceptions are specific to instructor type, and not class type. For example, regardless of type of class, professors are perceived as being confident, in control, organized, experienced, knowledgeable, distant, formal, strict, hard, boring, and respected. Conversely, GTAs are perceived as uncertain, hesitant, nervous, relaxed, laid-back, engaging, interactive, relatable, understanding, and able to personalize teaching. Overall, undergraduates seem to perceive professors as having more knowledge and authority over the curriculum, but enjoy the instructional style of GTAs. The results of this study will be used to make recommendations for GTA professional development programs.
\end{abstract}

\section{INTRODUCTION}

There is a growing dependence on contingent instructors (part-time, non-tenure-track faculty and graduate teaching assistants [GTAs]) at research universities (Johnson, 2011); specifically, Baldwin and Wawrzynski (2011) and Jaeger (2008) indicate that these contingent instructors may contribute to roughly half of the instructional staff. According to one survey in the biological sciences discipline in the United States $(n=65)$, GTAs are responsible for teaching $71 \%$ of undergraduate laboratory sections at their comprehensive institutions and 91\% at their research institutions (Sundberg et al., 2005). Similarly, Rushin et al. (1997) found that 97\% of 153 graduate schools surveyed in the United States used GTAs to

DOI: $10.1187 /$ cbe.11-10-0091

Address correspondence to: K. Denise Kendall (kkendal1@utk.edu).

(C) 2012 K. D. Kendall and E. E. Schussler. CBE—Life Sciences Education (C) 2012 The American Society for Cell Biology. This article is distributed by The American Society for Cell Biology under license from the author(s). It is available to the public under an AttributionNoncommercial-Share Alike 3.0 Unported Creative Commons License (http:/ / creativecommons.org/licenses/by-nc-sa/3.0).

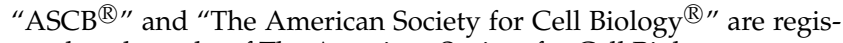
tered trademarks of The American Society for Cell Biology. teach laboratories and/or lectures in biology courses. While there may be variability in these numbers from institution to institution, they highlight the reliance of higher education on GTA employment.

The majority of contingent instructors provide instruction to lower-division courses, making the likelihood of contact with them greatest for first-year students. Given the importance of first-year coursework to student retention, understanding the impact of contingent instructors on student learning is critical (Benjamin, 2002; Jaeger, 2008). However, few studies have been conducted on the quality of teaching students receive from contingent instructors, and those that have been conducted report conflicting results or are limited by sample size (Umbach, 2007).

For instance, Bolge (1995) reported that contingent instructors do not differentially affect student outcomes, because there were no differences in final grades. Yet Johnson (2011) determined that contingent instructors typically give higher grades. It has also been reported that full-time, tenure-track faculty devote proportionately more time to students than do contingent instructors (Benjamin, 2002). Similarly, Jaeger (2008) noted that contingent instructors are generally less accessible and less available, even though students note that out-of-class interactions are most important for their education. Umbach (2007) suggested that contingent instructors 
are typically less effective in how they work with undergraduate students than tenured/tenure-track faculty. Yet Johnson (2011) reported that instructor type does not impact student retention, while O'Neal et al. (2007) found that GTA enthusiasm increased the likelihood of student retention. Baldwin and Wawrzynski (2011) posited that there is sufficient evidence to merit concern about the teaching quality of contingent instructors, and they are proponents of targeted professional development strategies for different types of contingent instructors. For this reason, this study focuses on identifying factors that undergraduates perceive as different between GTAs and professors in order to make suggestions specifically for GTA professional development.

\section{GTAs as Contingent Instructors}

While GTAs are used extensively as undergraduate instructors, they are admitted to universities to pursue graduate education at their institutions. Hence, some define a GTA as a graduate student pursuing a master's or doctoral degree who is used part-time to provide instruction to undergraduates, while also being involved in research and departmental degree requirements (Bos et al., 1980; Park and Ramos, 2002). However, departments may have jobs for GTAs other than instruction, which makes a generalizable definition difficult (Marincovich et al., 1998).

The perceived role of a GTA at an institution varies based on who is asked. For instance, undergraduates perceive GTAs as holding a status between students and academics, while GTAs see themselves as students with teaching responsibilities (Park, 2002; Muzaka, 2009). Faculty members consider GTAs to be research students who are also academic apprentices (Park, 2002; Muzaka, 2009). Their role is sometimes puzzling to administrators and policy makers, who are often unsure whether to classify GTAs as students or staff (Flora, 2007). Some studies attempting to clarify GTA responsibilities have gone as far as calling GTAs "donkeys of the department," due to their immense workload, level of responsibility, and restricted autonomy (Park and Ramos, 2002). Thus, GTAs occupy a unique position in the academic system as both researchers and faculty / teachers in training, whether by choice or not (Golde, 1998; Marincovich et al., 1998; Park, 2002; Park and Ramos, 2002; Muzaka, 2009).

\section{GTA Professional Development}

Given the reliance on GTAs for a majority of science laboratory teaching at U.S. universities, the need for effective professional development is a necessity. GTAs want preparation and guidance throughout their teaching experiences to improve not only their instructional ability but also their overall teaching experience (Bond-Robinson and Rodriques, 2006). Given that GTAs may be future faculty members at academic institutions, there is also a need to carefully mentor GTAs and provide them with advanced instructional assignments as they progress in their teaching experience (Braxton et al., 1995); however, GTA assignments are typically made to cover departmental needs and not the professional development needs of future faculty members (Austin, 2002). The reality is that GTAs often feel unprepared for their teaching assignments (Dudley, 2009), and most universities offer no formal professional training at all (Rushin et al., 1997).

A study by Rushin et al. (1997) surveyed graduate schools $(n=153)$ in the United States to determine what training opportunities they offer to GTAs. Although the most common response was that no formal training was required, the second most common approach was a pre-academicyear workshop (Rushin et al., 1997). The next most common GTA development opportunities, in decreasing prevalence, were: a semester-long college teaching seminar, a formal college teaching course, and training by a professor (Rushin et al., 1997). Typical professional development activities included teaching multiple courses during the graduate program, videotaping for self-evaluation, written training manuals, weekly meetings prior to teaching, and semester-long courses (Rushin et al., 1997), activities similar to those suggested by graduate students to improve their professional development as teachers (Nyquist et al., 1999). These findings are also similar to Marincovich et al. (1998), who found that the topics most commonly addressed in GTA professional development included teaching in a nontraditional setting, ethical issues, communication skills, developing reflection habits (including evaluating teaching skills), and obtaining frequent feedback (including close mentorship).

The Golde and Dore (2001) Pew Charitable Trusts study also asked doctoral students $(n=4114)$ from 11 Arts and Sciences departments about preparation for teaching. More than half of these doctoral students indicated they were required to teach during their degree program, and these students also reported that they were interested in, prepared for, and confident in teaching laboratory sections and lecture courses and in leading discussions (Golde and Dore, 2001). Yet Golde and Dore (2001) were unable to determine whether this confidence was merited, since graduate students clearly noted that their programs did not prepare them for these instructional roles.

Several researchers have indicated that even if departments provide instructional training, GTAs often receive minimal amounts of the pedagogical and content instruction information that they need (Marincovich et al., 1998; Shannon et al., 1998; Luft et al., 2004). Frequently absent from their training is the necessary background on delivering specific curricula, course planning, and assessment, or skills such as interdisciplinary connections, interactive pedagogy, instructional design, and teamwork (Marincovich et al., 1998; Shannon et al., 1998; Luft et al., 2004).

The offering of GTA professional development indicates that universities understand the importance of training; however, the diversity of training available and the reported lack of consistency in GTA training manuals (Lowman and Mathie, 1993) also indicates that more research needs to be done on what aspects of training are most beneficial to GTAs. Shannon et al. (1998), for instance, found that techniques such as microteaching, coteaching, and practice simulations were the most important aspects of developing teaching effectiveness in GTAs. They argue, however, that more progress will be made in determining the aspects essential to training when agreement is reached regarding the purpose and definition of GTA professional development (Shannon et al., 1998). This study responds to this call by identifying factors that undergraduates perceive to be different between GTAs and 
professors as one way to better understand what aspects need to be addressed in GTA professional development.

\section{Instructional Characteristics of GTAs}

Given the multiple roles of GTAs at universities, investigation of how the instructional role of a GTA might differ from that of a professor at a university seems warranted. Studies on this topic have been limited by several factors, however, including the overarching fact that many undergraduates are often unaware that those teaching them are GTAs (Park, 2002). There are also cultural differences, for instance, quality assurance, employment practices, and graduate recruitment procedures, between the higher education systems in which these studies have been performed (United States vs. United Kingdom) that hinder comparability of studies in different countries (Park, 2002). GTA studies are also difficult to compare, because most literature has focused on instructors who are tenure-line or ranked faculty members and few compare them directly with GTAs (Bos et al., 1980). GTAs also often teach different types of classes (e.g., laboratories or small discussions) than do faculty members.

However, several studies have looked specifically at GTA instructional characteristics and can be used to inform studies on this topic. One such study conducted by Dudley (2009) explored the role of a GTA, from the perspective of GTAs, to determine how they are able to balance their many responsibilities and still remain effective in the classroom. GTAs reported experiencing nervousness and intimidation, as well as concern that their teaching contradicted that of the professor. Dudley (2009) acknowledged that teaching requires training, practice, and revision, and that many GTAs draw from their own experiences as students to determine the best teaching style for their own classes. An important concluding factor is that GTAs must be able to overcome jitteriness while establishing authority in the classroom in order to be successful in the teaching environment (Dudley, 2009).

In another study, Park (2002) asked staff and GTAs to identify one positive and one negative aspect of GTA teaching. The positive aspects determined by this study included GTA characteristics of being approachable, informal, identifiable by undergraduates, enthusiastic, and good role models. Negative aspects included that the use of GTAs limits the access and contact time of students to academic experts (in terms of subject knowledge and teaching experience). Muzaka (2009) used methods similar to Park (2002), yet this study also took into account the perspective of undergraduates. Undergraduates, GTAs, and staff responded to open-ended questions asking about the most beneficial and most problematic aspects of GTA-led group seminars. Muzaka (2009) found that, from the undergraduate perspective, GTAs lack overall subject knowledge, teaching experience, confidence, control, and authority and are nervous. Yet undergraduates also indicated that GTAs identify easily with undergraduates and are understanding, flexible, informal, enthusiastic, approachable, and less intimidating. Characteristics identified from GTA and staff perspectives included GTA lack of ability to guarantee consistency, lack of overall subject knowledge, and limited teaching skills (Muzaka, 2009).

While the previous studies were qualitative, Bos et al. (1980) quantitatively analyzed student ratings of their GTAs to identify characteristics that may impact the effectiveness of in- struction. This study resulted in the generalizations that GTA ratings are not impacted by undergraduate student major and gender of the GTA, yet they are influenced by degree held (higher degrees result in higher ratings), teaching experience, and GTA age (those in their late twenties are rated higher than those in their early twenties; Bos et al., 1980).

\section{Project Rationale}

Previous studies have found that there are instructional characteristics of GTAs that impact the perception of teaching and learning at universities; however, there have been few direct comparisons of student perceptions of professors and GTAs, particularly those employing the same methodologies on the same undergraduate student population. The goal of this study is to provide a quantitative and qualitative comparison of professors and GTAs from the perspective of undergraduate students at one institution in order to identify factors useful for GTA professional development. Although professors and GTAs may teach similar content and students, they often teach different types of classes, which could confound the identification of variables specific to each type of instructor. Thus, this study is designed to identify factors unique to each type of instructor, versus the type of classes they teach, by collecting data on undergraduate student perception of each type of instructor in each of two classroom situations (laboratory and discussion). The hypothesis for this study is that undergraduates will perceive a difference between professors and GTAs related to the instructor and not just the classroom environment.

\section{MATERIALS AND METHODS}

\section{Data Collection}

Data were collected through an online survey (hosted by surveymonkey.com) composed of subscales from two published and validated instruments, the College and University Classroom Environment Inventory (CUCEI) and the Questionnaire of Teacher Interaction (QTI).

These instruments were chosen for this study as they best captured the previously identified instructional characteristics of GTAs (e.g., uncertainty, approachable, etc.), and both had been used individually and together in previous studies in the college environment (Treagust and Fraser, 1986; Coll et al., 2002). The CUCEI was designed to incorporate the dimensions identified by Moos (1979) in his work on classroom environment and includes the subscales of: Personalization, Innovation, Student Cohesiveness, Satisfaction, Task Orientation, Innovation, and Individualization (Treagust and Fraser, 1986; Coll et al., 2002). The QTI was originally designed in the Netherlands to explore how individuals mutually influence each other and consists of 77 items; however, it was shortened to 48 items for use in the Australian science education environment (Coll et al., 2002). The shortened QTI covers the subscales of: Leadership, Understanding, Uncertain, Admonishing, Helpful/Friendly, Student Responsibility and Freedom, Dissatisfied, and Strict (Coll et al., 2002).

Using both the CUCEI and QTI instruments in their entirety would result in a survey requiring responses to 97 items, not 
Table 1. The CUCEI subscales and items used for the study ${ }^{a}$ Subscale Items

Individualization All students in the class are expected to do the same work, in the same way and in the same time.

It is the instructor who decides what will be done in our class.

Students are allowed to choose activities and how they will work.

Students are generally allowed to work at their own pace.

Students have a say in how class time is spent.

Teaching approaches allow students to proceed at their own pace.

There is little opportunity for a student to pursue his/her particular interest in this

Involvement class.

Students "clockwatch" in this class.

Students in this class pay attention to what others are saying.

Students put effort into what they do in classes.

Students seldom present their work to the class.

The instructor dominates class discussion.

The instructor talks rather than listens.

There are opportunities for students to express opinions in this class.

Personalization The instructor considers students' feelings.

The instructor goes out of his/her way to help students.

The instructor helps each student who is having trouble with the work.

The instructor is unfriendly and inconsiderate toward students.

The instructor isn't interested in students' problems.

The instructor seldom moves around the classroom to talk with students.

The instructor talks individually with students.

Task Orientation Class assignments are clear so everyone knows what to do.

Getting a certain amount of work done is important in this class.

Students know exactly what has to be done in our class.

The group often gets sidetracked instead of sticking to the point.

This class seldom starts on time.

This is a disorganized class.

Activities in this class are clearly and carefully planned.

a Undergraduates rated whether they "strongly agree" (5), "agree" (4), "disagree" (2), or "strongly disagree" (1). The items include both positive and nonpositive items (underlined) about the class.

all of which were necessarily relevant to the study. Given the voluntary nature of the survey, and since not all of the subscales were directly related to potential differences between GTAs and professors (based on previous research), it was determined that only certain subscales of each instrument would be used in the study. Therefore, this project utilized only the CUCEI subscales of Personalization, Involvement, Task Orientation, and Individualization. For the QTI, only the subscales of Leadership, Uncertain, Helpful/Friendly, and Strict were used. The subscales were chosen to best capture aspects that were similar to the results of previous research,
Table 2. QTI subscales and items used in the study ${ }^{\mathrm{a}}$

Subscale Items

Helpful/Friendly This teacher can take a joke.

This teacher has a sense of humor.

This teacher helps us with our work.

This teacher is friendly.

This teacher is someone we can depend on.

This teacher's class is pleasant.

Leadership This teacher acts confidently.

This teacher explains things clearly.

This teacher holds our attention.

This teacher is a good leader.

This teacher knows everything that goes on in the classroom.

This teacher talks enthusiastically about her/his subject.

Strict This teacher is severe when marking papers.

This teacher is strict.

This teacher's standards are very high.

This teacher's tests are hard.

We are afraid of this teacher.

We have to be silent in this teacher's class.

Uncertain It's easy to be off task with this teacher.

This teacher acts as if she/he does not know what to do.

This teacher is hesitant.

This teacher is not sure what to do when we are not on task.

This teacher lets us boss her/him around.

This teacher seems uncertain.

${ }^{a}$ Undergraduates rated how often they believed an instructor would do this: 4 being "always," down to 0 , which was "never."

such as positive aspects of GTA instructors (e.g., approachability, informality, enthusiasm, and less intimidating, which related to the CUCEI and QTI subscales of Helpful/Friendly, Personalization, Task Orientation, Leadership, and Strict), and negative aspects (e.g., lack of experience, control, and content knowledge, and limited contact time, which related to the CUCEI and QTI subscales of Leadership, Task Orientation, Uncertain, Individualization, and Involvement; Bos et al., 1980; Park, 2002; Dudley, 2009; Muzaka, 2009). The subscale questions, as well as the Likert choices undergraduates were given for each, are shown in Tables 1 and 2 .

The survey was sent via email in September 2010 (4 weeks into the Fall semester) to undergraduate students enrolled in majors and nonmajors general biology courses (introductory biology, plant biology, biodiversity, cell biology, genetics, and ecology) at a large research institution in the southern United States. Each of the selected courses has a lecture and laboratory component; the laboratories are all taught by GTAs, who teach two or three laboratory sections per semester, and the lecture classes are all taught by PhD-level faculty (tenureline or lecturers). Undergraduate students received the email, which contained a description of the project and a link to the survey, from their lecture instructor on behalf of the researcher. The communication was done via the lecture and not the laboratory, because more undergraduates would receive the information at one time and much of the course communication is routinely done through the lecture instructor. The project description indicated that responding to the survey was voluntary and was not related to the course grade; 
additionally, undergraduates were assured that their instructor would not see their responses to the survey. Throughout the survey, undergraduates were asked to focus on generic and not specific instructors.

Prior to beginning the survey, undergraduate students responded to demographic questions about their gender, enrollment status, major, native language, and other biology courses they had completed. Student participants then answered the same set of survey questions but were assigned (by their last name for each lecture class) to only one of four scenarios: 1) imagine a small discussion class (20-25 students) taught by a professor, 2) imagine a small discussion class (2025 students) taught by a GTA, 3) imagine a lab class (20-25 students) taught by a professor, or 4) imagine a lab class (2025 students) taught by a GTA.

After respondents were informed of their scenario, they responded to items from the CUCEI. The original directions for the CUCEI were included, and students were told to respond to each item using a four-point scale of "strongly disagree," "disagree," "agree," and "strongly agree." The order the items were presented in was similar to the methodology in Coll et al. (2002) and Treagust and Fraser (1986) to be consistent with previous studies. After students completed the CUCEI items, they were presented with directions for the QTI. The response options were on a five-point scale ranging from " 0 " (the instructor never displays this behavior) to " 4 " (the instructor always displays this behavior). The QTI items were presented in an order similar to that used by Coll et al. (2002). Students were unable to change their responses once they had completed a page. Undergraduates were also asked to confirm their scenario at the end of the survey to allow the researcher to remove responses from undergraduates who might have forgotten their scenario midsurvey. After responding to the CUCEI and QTI items, all undergraduate students then responded to the same open-ended question: If the same class was taught by a professor versus a graduate teaching assistant, how do you think the classes would be different?

No incentives were offered for participation, and all procedures were reviewed and approved by the Institutional Review Board for Human Subjects.

\section{Survey Validity and Reliability}

Because this project used two pre-existing instruments (both previously validated) in the same survey, with four different scenarios, internal consistency/reliability estimates were calculated for each subscale, as well as for each subscale for each scenario, using Cronbach's alpha. For the overall data, these values ranged from 0.655 to 0.876 , depending on the subscale, and were higher than those reported for previous uses of the instruments in college environments, except for the subscale of Individualization (Coll et al., 2002; Treagust and Fraser, 1986). For the subscales by scenarios, the reliability measures varied from 0.580 to 0.911 for each subscale. From these results, it was judged that the instruments were reliable to use for the project.

Validity of the open-response question was judged via face validity, in that most students responded to the question and gave responses that were consistent with the intent of the question. No students wrote that they did not understand what the question was asking.

\section{Data Analysis}

Quantitative Data. Data from the CUCEI and QTI subscales were coded independently, due to differences in the Likert scaling. The CUCEI responses were coded in the following manner: "strongly agree" $=5$, "agree" $=4$, "disagree" = 2 , and "strongly disagree" $=1$. Nonpositive items (see Table 1) were "flipped" and then coded: "strongly agree" =1, "agree" $=2$, "disagree" $=4$, or "strongly disagree" $=5$. The QTI was coded in the following manner: responses of "always" were scored as " 4 ," and then coding progressed down to "never," which was scored as "0." No questions from the QTI were nonpositive. Student responses for each scenario were then compiled for comparison.

The quantitative data were analyzed using nonparametric methodology, because the Likert-type choices are ordinal. In ordinal data, there is no guarantee that students perceive the difference between intervals on the point scale as equal distances (e.g., "agree" and "strongly agree" are at the same distance as "agree" and "disagree"). This theoretical lack of equal distances violates assumptions for parametric methodology, requiring the data to be analyzed via nonparametric tests (Huck, 2008).

For each of the CUCEI and QTI items, student responses among each of the four scenarios were compared using Kruskal-Wallis one-way analysis of variance (ANOVA) tests (SPSS Statistics 19.0). Items in which statistically significant differences were found $(\alpha<0.05)$ were then compared using pairwise comparisons (Mann-Whitney $U$-tests, with Bonferroni approach to control for type I error across tests $[\alpha<$ 0.013]). Pairwise comparisons were performed to determine whether the differences were due to the classroom setting or instructor type; the former were considered to be "classroom variables" and the latter were considered to be "instructor variables." Significant classroom variables were identified by comparing professors in a discussion class with professors in a lab class and GTAs in a discussion class to GTAs in a lab class, while instructor variables were identified by comparing professors in a discussion class with GTAs in a discussion class and professors in a lab class to GTAs in a lab class.

The majority of undergraduate participants were firstyear students (53\%); consequently, Kruskal-Wallis one-way ANOVA tests were performed to determine whether student enrollment status affected the results. It was found that responses from first-year students did not differ from second-, third-, fourth-year, and beyond students; therefore, undergraduate students were grouped together for all analyses.

Qualitative Data. Open-ended responses $(n=127)$ to the question about differences between a class taught by a GTA versus a professor were first sorted into responses that indicated there would be no difference and those that stated there would be a difference. Undergraduate student responses in which differences were perceived $(n=110)$ then underwent thematic analysis using a "grounded theory" approach (Corbin and Strauss, 1990; LeCompte, 2000) in which the researchers let the results emerge from the data without preconceived ideas about what students might articulate. Responses were analyzed independently by two researchers (each author of this paper) who read and reread the responses and took notes on the differences undergraduates articulated about the two different types of instructors. Factors that arose consistently were grouped and given a name (key word) and 
description, and then each researcher tallied the number of times those key words or descriptions appeared in student responses. Each researcher then compiled her findings, and only then did the researchers compare their results. The identified key words were then grouped into themes via discussion between the two researchers until both were in agreement.

As an example of this process, student responses yielded the key word "relatable" as one possible emergent characteristic of GTAs. Student responses that indicated that GTAs identified with them, related to them, knew what it was like to be in a student's shoes, were classified into this category. This key word of "relatable" was then merged with other key words (such as "respect," "boring," and "approachable") into a theme that was entitled "relationship," because they all were thought to be articulating how students and instructors interact on a personal level (one on one, not just in a classroom delivery setting).

Reliability of these results was first obtained by the concordance of key words and descriptions between the two authors. Even if the key words were different, the ideas captured from the student responses were the same, and the researchers discussed the final title of the key word to reach consensus. The results also aligned with several of the quantitative results of this study (e.g., uncertain and nervous), as well as the results of previous studies (e.g., approachable, relatable, uncertain, nervous, and limited control [Park, 2002; Dudley, 2009; Muzaka, 2009]). These multiple sources of verification of the results were considered evidence of the reliability of the findings.

\section{RESULTS}

\section{Participants}

The survey was sent to a potential undergraduate pool of 2586 undergraduate students. From this pool, 387 began the survey $(15.0 \%)$, while 225 undergraduates completed the survey $(8.7 \%)$. Undergraduates who were minors or who could not remember their scenario at the end of the survey were removed, leaving 184 total respondents $(7.1 \%)$. This response rate was likely a result of the survey being voluntary, with no incentives for participation. Of the 184 respondents, survey completion for each scenario was: 59 for a discussion class taught by a professor; 43 for a discussion class taught by a GTA; 38 for a lab class taught by a professor; and 44 for a lab class taught by a GTA. There were 167 undergraduates who responded to the open-ended question. After removing responses in which the instructor they were referring to was indeterminable (e.g., "They are more understanding"), 127 respondents remained for analysis.

Individuals who completed the survey were mostly freshman (first year; 53\%), non-biology majors (74\%), female $(72 \%)$, and native English speakers (95\%). Second- and thirdyear students comprised 21 and $18 \%$, respectively, of the respondents, with $8 \%$ more being fourth year or beyond. Twenty-six percent of the students were biology majors, with $4 \%$ concentrating in ecology and evolutionary biology, 10\% in biochemistry and cellular and molecular biology, and 3\% in microbiology. Most of the respondents were currently enrolled in a majors' biology course (62\%), while the rest were currently enrolled in nonmajors courses. The majority of respondents had not completed another biology course (63\%); however, $37 \%$ had completed at least one other semester-long lecture/lab biology course, such as first semester nonmajors biology (11\%), biodiversity (17\%), and cell biology (13\%). A complete summary of the demographics for overall survey respondents, as well as demographics for each scenario, is shown in Table 3.

\section{Quantitative Analysis}

Item Analysis. Items from each survey in which significant differences in the medians among the scenarios were found (Kruskal-Wallis; $\alpha<0.05$ ) are shown in Table 4 . Descriptive statistics for each of these items for each scenario are shown in Table 5. These items included: students knowing what to do in class $\left(\chi^{2}=7.95, d f=3, n=183, p=0.047\right)$, having a say in how class time is spent $\left(\chi^{2}=7.821, d f=3, n=184, p=0.050\right)$, class being disorganized $\left(\chi^{2}=8.264, d f=3, n=184, p=0.041\right)$, students being allowed to choose activities and how they will work $\left(\chi^{2}=9.004, d f=3, n=181, p=0.029\right)$, students having opportunities to express their opinions in class $\left(\chi^{2}=10.976\right.$, $d f=3, n=184, p=0.012)$, activities being clearly and carefully planned $\left(\chi^{2}=13.09, d f=3, n=184, p=0.004\right)$, the teacher talking enthusiastically about the subject $\left(\chi^{2}=24.098, d f=3\right.$, $n=184, p=0.000)$, the teacher being uncertain $\left(\chi^{2}=16.20\right.$, $d f=3, n=184, p=0.001)$, the teacher being hesitant $\left(\chi^{2}=\right.$ 10.628, $d f=3, n=183, p=0.014)$, and the teacher knowing what to do $\left(\chi^{2}=17.319, d f=3, n=184, p=0.001\right)$. These significant differences spanned items from five of the eight subscales of the two instruments, including Task Orientation, Individualization, Involvement, Leadership, and Uncertain.

Pairwise Comparisons. To determine whether the significant differences among scenarios were a result of classroom or instructor variables, pairwise comparisons were completed between classroom scenarios and then between instructor scenarios for each significant item. The comparisons among classroom scenarios (a GTA teaching a lab vs. teaching a discussion, or a professor teaching a lab vs. teaching a discussion) found no differences between any of the scenarios (Table 4). These results indicate that undergraduates in this study perceive instructor qualities to be the same in discussion classrooms as in lab classrooms.

For instructor variables (a GTA vs. a professor teaching the same type of class), there were no significant differences in responses between a professor teaching a discussion class and a GTA teaching a discussion class. However, undergraduates perceived differences in a professor teaching a lab class and a GTA teaching a lab class. In the situation of the professor and GTA both teaching a lab class, significant differences in undergraduate responses occurred in the factors of planning $(U=570.500, n=81, p=0.004)$, enthusiasm $(U=373.500, n=$ $81, p=0.000)$, uncertainty $(U=553.500, n=81, p=0.005)$, hesitation $(U=518.000, n=81, p=0.002)$, and knowing what to do $(U=464.500, n=81, p=0.000)$, spanning items from three (Task Orientation, Leadership, and Uncertain) of the eight subscales from the two instruments used in this study (Table 4). Thus, when professors and GTAs are in lab classrooms, students in our study indicated that professors are 
Table 3. Demographic percentages for overall study participants, as well as by scenario ${ }^{\mathrm{a}}$

\begin{tabular}{|c|c|c|c|c|c|}
\hline & Overall & Discussion professor & Discussion GTA & Lab professor & Lab GTA \\
\hline \multicolumn{6}{|l|}{ What is your gender? } \\
\hline Male & $28 \%$ & $29 \%$ & $30 \%$ & $29 \%$ & $23 \%$ \\
\hline Female & $72 \%$ & $71 \%$ & $70 \%$ & $71 \%$ & $77 \%$ \\
\hline \multicolumn{6}{|l|}{ What is your current enrollment status? } \\
\hline First year & $53 \%$ & $58 \%$ & $49 \%$ & $39 \%$ & $61 \%$ \\
\hline Second year & $21 \%$ & $22 \%$ & $28 \%$ & $26 \%$ & $9 \%$ \\
\hline Third year & $18 \%$ & $15 \%$ & $14 \%$ & $21 \%$ & $23 \%$ \\
\hline Fourth year & $6 \%$ & $3 \%$ & $5 \%$ & $11 \%$ & $7 \%$ \\
\hline Fifth year and/or beyond & $2 \%$ & $2 \%$ & $2 \%$ & $3 \%$ & $0 \%$ \\
\hline \multicolumn{6}{|l|}{ What is your major? } \\
\hline Biology & $9 \%$ & $7 \%$ & $12 \%$ & $3 \%$ & $14 \%$ \\
\hline Ecology and evolutionary biology & $4 \%$ & $2 \%$ & $2 \%$ & $8 \%$ & $5 \%$ \\
\hline Biochemistry, cellular, and molecular biology & $10 \%$ & $10 \%$ & $5 \%$ & $13 \%$ & $11 \%$ \\
\hline Microbiology & $3 \%$ & $0 \%$ & $2 \%$ & $3 \%$ & $7 \%$ \\
\hline Other & $74 \%$ & $81 \%$ & $79 \%$ & $74 \%$ & $64 \%$ \\
\hline \multicolumn{6}{|l|}{ Is English your native language? } \\
\hline Yes & $95 \%$ & $93 \%$ & $98 \%$ & $100 \%$ & $98 \%$ \\
\hline No & $4 \%$ & $7 \%$ & $2 \%$ & $0 \%$ & $2 \%$ \\
\hline \multicolumn{6}{|l|}{ What other core courses have you completed? } \\
\hline First semester nonmajors biology & $11 \%$ & $15 \%$ & $5 \%$ & $13 \%$ & $11 \%$ \\
\hline Second semester nonmajors biology & $8 \%$ & $8 \%$ & $7 \%$ & $11 \%$ & $7 \%$ \\
\hline First semester plant biology & $2 \%$ & $2 \%$ & $2 \%$ & $5 \%$ & $0 \%$ \\
\hline Second semester plant biology & $2 \%$ & $2 \%$ & $2 \%$ & $3 \%$ & $0 \%$ \\
\hline Biodiversity & $17 \%$ & $14 \%$ & $14 \%$ & $24 \%$ & $23 \%$ \\
\hline Honors biodiversity & $1 \%$ & $3 \%$ & $0 \%$ & $0 \%$ & $0 \%$ \\
\hline Cell biology & $13 \%$ & $7 \%$ & $12 \%$ & $18 \%$ & $18 \%$ \\
\hline General genetics & $6 \%$ & $3 \%$ & $7 \%$ & $8 \%$ & $7 \%$ \\
\hline General ecology & $1 \%$ & $0 \%$ & $0 \%$ & $3 \%$ & $2 \%$ \\
\hline No others & $63 \%$ & $66 \%$ & $69 \%$ & $50 \%$ & $66 \%$ \\
\hline \multicolumn{6}{|l|}{ Current course enrollment } \\
\hline First semester nonmajors biology & $38 \%$ & $49 \%$ & $38 \%$ & $29 \%$ & $30 \%$ \\
\hline First semester plant biology & $4 \%$ & $2 \%$ & $10 \%$ & $3 \%$ & $2 \%$ \\
\hline Biodiversity & $34 \%$ & $31 \%$ & $38 \%$ & $29 \%$ & $41 \%$ \\
\hline Honors biodiversity & $3 \%$ & $5 \%$ & $0 \%$ & $3 \%$ & $5 \%$ \\
\hline Cell biology & $8 \%$ & $7 \%$ & $5 \%$ & $18 \%$ & $5 \%$ \\
\hline General genetics & $7 \%$ & $5 \%$ & $7 \%$ & $3 \%$ & $11 \%$ \\
\hline General ecology & $7 \%$ & $2 \%$ & $5 \%$ & $16 \%$ & $7 \%$ \\
\hline
\end{tabular}

more enthusiastic and have activities more clearly and carefully planned, while GTAs are more uncertain, hesitant, and act as if they do not know what to do. These results are similar to those obtained from the qualitative data (see below), except the factor of enthusiasm, which was not mentioned by undergraduates in the open-ended responses.

\section{Qualitative Analysis}

While $\sim 13 \%$ ( $n=17$ ) of the undergraduate student respondents indicated that they would not perceive a difference in a class taught by a professor versus a GTA, analysis of the responses from undergraduates who did perceive differences $(n=110)$ generated two overall themes: factors relating to the teaching realm (further subdivided into themes of delivery technique and classroom atmosphere) and factors related to the personal realm (particularly with regard to relationship). The delivery technique, classroom atmosphere, and relationship themes are explained in Table 6 by using the key words and main descriptions researchers used to characterize undergraduate perceptions of the differences between GTAs and professors in the open-ended question. The numbers in parentheses after each bold descriptive key word indicate the number of times responses were grouped into those key words. A single student response could contain anywhere from zero to three key words (mean $=1.4$ key words). These perceived differences between GTAs and professors were identified as instructor variables and not classroom variables, since participants were asked about how GTAs and professors would differ in teaching the same type of class.

The theme of delivery technique includes student responses that seemed to reflect the characteristics of the instructors as teachers, specifically how they deliver the course material to students and how confident the instructor appears in the classroom. This theme incorporated responses that referenced classroom control, organization and preparedness, knowledge level, and teaching experience. Undergraduates described professors as being more experienced, structured, confident, knowledgeable, organized, and in control in the classroom as compared with GTAs, who undergraduates described as more hesitant, nervous, and uncertain. For instance, student 58 stated, "TAs tend to be unorganized, without a strong curriculum to back them up, nor do they have the teaching experience that gives them the courage to stand 


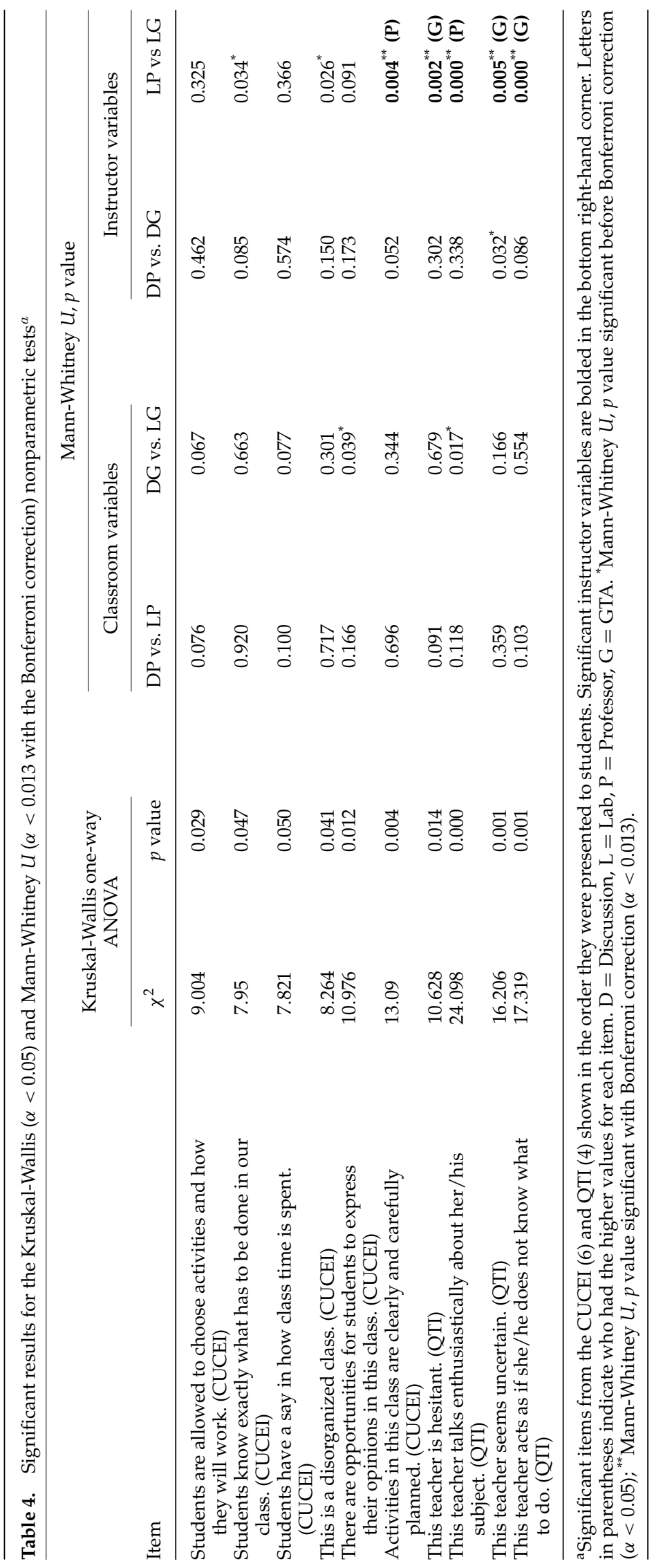




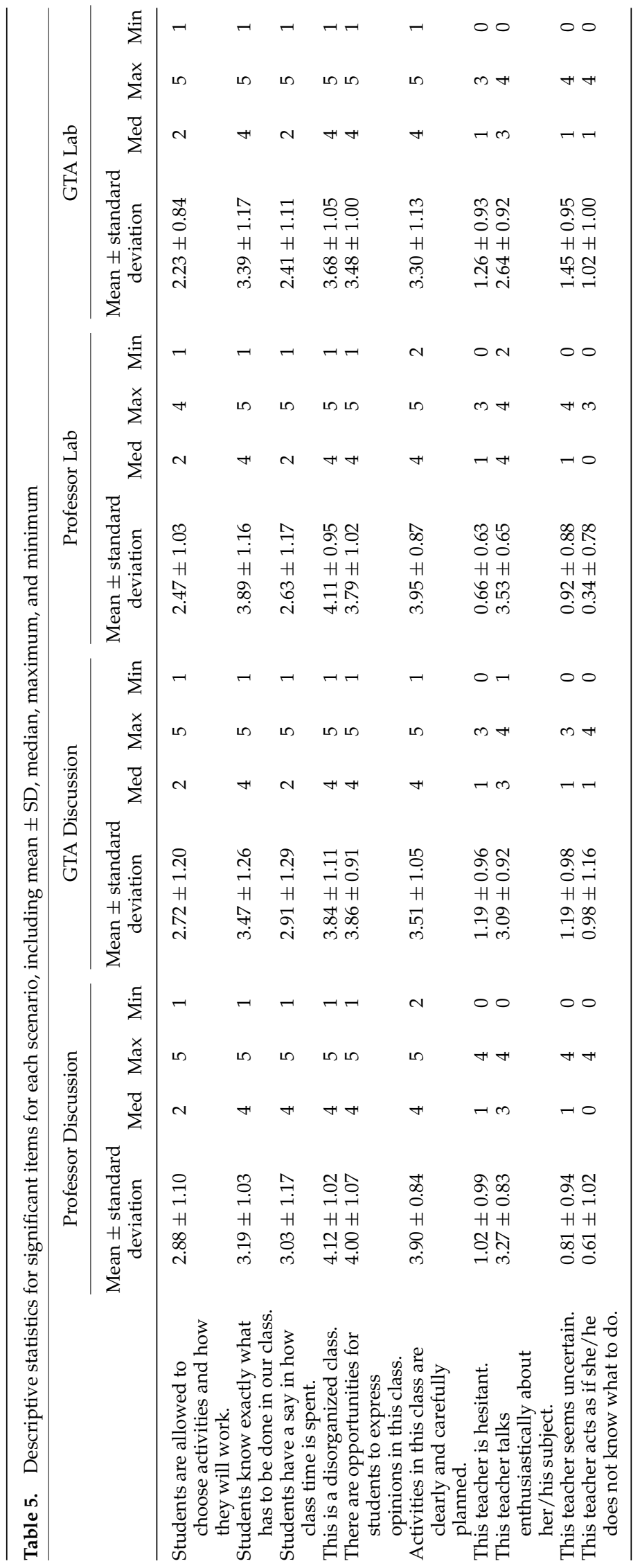


Table 6. Summary of themes (delivery technique, classroom atmosphere, and relationship) obtained from qualitative data in both the teaching and personal realms for GTAs and professors ${ }^{\mathrm{a}}$

\begin{tabular}{|c|c|c|c|}
\hline Realm & Theme & GTA & Professor \\
\hline \multirow[t]{2}{*}{ Teaching } & Delivery technique & $\begin{array}{l}\text { Hesitant, nervous, uncertain (11), and } \\
\text { unsure how to begin teaching }\end{array}$ & $\begin{array}{l}\text { Organized and structured (17), confident (10), } \\
\text { in control (10), prepared for questions, with } \\
\text { previous teaching experience (15), and } \\
\text { greater knowledge (21) }\end{array}$ \\
\hline & Classroom atmosphere & $\begin{array}{l}\text { Relaxed and laid-back (9), interactive, } \\
\text { engaging (5), personalized, and } \\
\text { having open student-instructor } \\
\text { interactions (3) }\end{array}$ & $\begin{array}{l}\text { Distant and formal (9), strict (13), serious, } \\
\text { harder (2), with higher expectations and } \\
\text { standards }\end{array}$ \\
\hline Personal & Relationship & $\begin{array}{l}\text { Comfortable approaching GTAs (8) } \\
\text { and that GTAs are relatable (19) and } \\
\text { understanding (5) }\end{array}$ & $\begin{array}{l}\text { Intimidating and boring }(2) \text {, and out of touch } \\
\text { (6), yet undergraduates respect (14) } \\
\text { professors }\end{array}$ \\
\hline
\end{tabular}

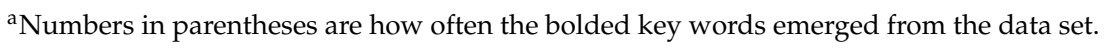

before students and confidently teach the material." Meanwhile, student 153 elaborated on this by saying, "Professors are usually more confident and know the subject or lab better. GTAs are always a little uncertain and don't always answer questions well." The key words that comprised this theme were the most common responses by undergraduates to the open-ended question, especially in terms of the knowledge $(n=21)$, structure/organization $(n=17)$, and experience $(n=$ 15) of professors being greater than that of GTAs.

The classroom atmosphere theme grouped student comments that seemed to be about student-instructor relationships within the context of classroom instruction. Undergraduates in the study articulated that the classroom atmosphere with a professor was more distant, strict, and formal, as compared with that of a GTA, whose classroom was seen as more relaxed, laid-back, and personalized. Furthermore, some undergraduates expressed that professor-led classrooms had higher expectations and were more serious than GTA-led classrooms, which some undergraduates indicated were more interactive and engaging. For instance, student 60 said, "The professor might be more strict rather than a graduate teaching assistant who might be a little more laid back because they can relate to the stress of college and how they might have had a bad teacher or hard professor." Student 156 explained, "Professors are typically old and out of touch with the students. They are set in their ways about their classes, and tend to lecture blandly. Graduate TAs seem to be more engaging." In this theme, the most prevalent distinction made by undergraduates was the strictness $(n=13)$ and formality $(n=9)$ of professors in comparison with GTAs, who were perceived as more relaxed and laid-back $(n=9)$.

The relationship theme featured comments that seemed to be about person-to-person interactions, such as the comfort level and identifiability between students and instructor. For example, professors were perceived as being boring and out of touch, yet respected, while GTAs were seen as approachable, understanding, and relatable. Student 132 explained, "People may feel that they could approach a grad assistant, whereas they might be threatened by a professor." Student 163 commented, "I believe we would respect the Professor more than the Graduate Teaching Assistant. Just because the TA's are younger and look pretty much like our friends therefore making them look younger and less serious." In terms of the relationship aspect, undergraduates noted their respect for professors $(n=14)$ and their ability to relate to GTAs $(n=$ 19) as the primary descriptors.

\section{DISCUSSION}

Bos et al. (1980) suggested caution when comparing different studies regarding GTA instructional abilities with ones for ranked faculty members; our study has addressed this concern through comparison of GTAs and professors in the same study using the same sample population and instruments. This study has further addressed the call for developing targeted professional development (Shannon et al., 1998; Baldwin and Wawrzynski, 2011) by identifying aspects that distinguish GTAs from faculty and that could be the focus of professional development.

We hypothesized that undergraduates would perceive differences between GTAs and professors that were independent of classroom variables and found evidence that supported this hypothesis. Undergraduates in this study perceived professors as being more structured, confident, in control, organized, experienced, knowledgeable, distant, formal, strict, serious, hard, boring, out of touch, and respected than GTAs. Conversely, GTAs were perceived as more uncertain, hesitant, nervous, relaxed, laid-back, engaging, interactive, relatable, understanding, and able to personalize teaching than professors.

Significant differences between instructor type were found for five of the 52 items surveyed in the quantitative portion of this study, while no significant classroom variables were identified. Thus, although students do see many similarities between professors and GTAs, there are also core factors that undergraduates at one institution say are different between GTAs and professors independent of what classes they teach. These results were supported by the qualitative data analysis, which independently confirmed four of the five instructor differences from the quantitative analysis. In addition, the openresponse format allowed students to add additional variables that were not identified from the survey.

Although it remains to be seen whether the results of this study are broadly applicable (see Limitations), they can be used as the starting point for investigating classroom practice and pondering the stereotypes that students may carry with them into classrooms. For instance, undergraduates appear to have positive feelings about how professors organize and 
understand the content they teach, and respect them overall, but they also appear to have more negative views of their abilities to relate to undergraduates and understand them. Conversely, undergraduates have some negative perceptions of GTAs' abilities to convey information instructionally, but they have very positive feelings about GTAs' abilities to interact with them. It is important to point out that these results do not seem to indicate that GTAs are less favored as instructors compared with professors; however, the stereotypes articulated by undergraduates almost surely impact the teaching and learning environment in undergraduate classrooms. Even if an individual GTA or professor does not adhere to the identified stereotypes, they are likely being compared with this typical perception, which may impact how students react to them in the classroom.

Our results are similar to those obtained by Park (2002) and Muzaka (2009) in which GTAs, staff, and undergraduates indicated that GTAs were understanding, approachable, laid-back, and nervous; have limited control and authority; and lack content knowledge and experience. Yet Park (2002) and Muzaka (2009) found that GTAs exhibit a youthful enthusiasm, while undergraduates from our study indicated that GTAs are less enthusiastic than professors. This may be a result of this study asking students to directly compare GTAs with professors, or because these data were collected solely from undergraduates. These differences may also be attributable to culture, since the work done by Park (2002) and Muzaka (2009) was completed in the United Kingdom, while our study took place in the United States. Our study also focused specifically on introductory courses in which laboratories function somewhat separately from lecture (taught by different instructors in different locations with different class sizes), whereas other institutions may have a different course structure. There are also different selection processes for GTAs at different universities, with some GTAs volunteering or being more enthusiastic about teaching, while GTAs at a research university may not be as enthusiastic or have the time or encouragement to embrace their teaching duties.

It is also now possible to compare the perceptions of undergraduates in this study with reflections of GTAs on their own teaching characteristics. Dudley (2009) documented instructor variables of GTAs from the perspective of GTAs. These GTAs expressed ideas such as: confusion with expectations, difficulty establishing boundaries, dealing with nervousness, expectation to be knowledgeable, and being uncertain where to start. The variables of nervousness and being uncertain about where to start were also identified as characteristics of GTAs by undergraduates in our study. The variables of confusion with expectations, difficulty establishing boundaries, and expectation to be knowledgeable identified by Dudley (2009) are similar to the lack of experience, control, and knowledge that undergraduates identified with GTAs in this study. These similarities in the perceptions of GTAs by GTAs themselves and undergraduates may be explained by the fact that GTAs see themselves as students who merely have teaching responsibilities (Park, 2002; Muzaka, 2009).

\section{Proposed Explanations of Instructor Differences}

The aspects that undergraduates perceive as different between GTAs and professors may have their origin in factors that are specific to the academic context, such as who has control over the curriculum and the status of the instructor (faculty or not faculty). When using these factors to explain the themes (delivery technique, classroom atmosphere, and relationship) it should be acknowledged that one factor may influence several aspects of instructor perception. Some of these factors will be highlighted below by providing literature that explains differences between student perceptions of GTAs and professors for each of the themes identified in this study.

One factor that may contribute to undergraduate perception of the instructor's delivery technique is the curriculum. Professors typically have more control over the organization of the curriculum and classroom policies, while GTAs are typically given specific assignments within the curriculum to enact, with oftentimes little opportunity to alter or modify it. This was articulated in a study by Park and Ramos (2002), in which GTAs expressed they had little autonomy or ownership over what they taught, but were merely "carrying out the job," and a study by Muzaka (2009), in which GTA lack of control and authority over the curriculum led to a perception that students "see no point to us." The perception of "control," however, could also be due to professors having a greater student-teacher distance, due to status, age, and possibly greater confidence in the subject matter (Roach, 1997). For undergraduates in our study, these factors may have contributed to their feelings of their GTAs being hesitant and uncertain about what they were teaching and their professors being confident, knowledgeable, and organized.

The classroom atmosphere theme appears to be influenced by the perception of instructor behavior in the classroom. For instance, GTAs are perceived as being engaging and laidback, while professors are more distant and formal. Even though the classroom itself was not perceived by students as a distinguishing variable, it could be that the size of the classroom affects classroom teaching behavior. GTAs often teach smaller sections (laboratories and discussion sections) in which students are able to interact with them on a oneon-one basis, while professors often have larger classes in which it is more difficult to interact with students individually (Dudley, 2009). Professors may also appear more distant due to knowledge level and age differences, which may limit the interactions they have with students (Anderson and Carta-Falsa, 2002). Undergraduates may also perceive that since GTAs are typically similar in age to them, they can better relate to their classroom experiences and explain things to them (Muzaka, 2009).

Certainly, this perception of engagement is a positive aspect of GTA instruction. Darby (2005) concluded that when GTAs are enthusiastic about the subject matter, students are more comfortable with the subject matter and their learning is better supported. Similarly, O'Neal et al. (2007) determined that GTA enthusiasm positively impacts student retention in the sciences. This may be attributed to engaged students being more likely to learn and retain knowledge (Umbach and Wawrzynski, 2005).

For the theme of relationship, instructor age may be a factor influencing student perception. GTAs are typically younger than faculty members, and thus could be perceived by the undergraduates as closer to their own age and therefore more approachable (Muzaka, 2009). GTAs and undergraduates also have similar experiences, because GTAs are often still taking graduate classes while they are teaching (Park and Ramos, 
2002; Dudley, 2009). Thus, undergraduates may think that since GTAs are more familiar with academic demands, the pressures of deadlines, and workload in their own courses and research, they may be more understanding, approachable, and relatable when undergraduates express workload issues (Muzaka, 2009). Greater age, status, and confidence (Roach, 1997) may also be why undergraduates in this study afforded professors more respect than GTAs.

\section{Limitations}

One limitation of this study is the small sample size and the fact that it was conducted on a limited subset of volunteer participants in one discipline at one university. The sample was also greatly overrepresented by first-year, female, nonbiology major undergraduates. This particular sample may have had limited experience with instructors of various titles (GTA vs. professor), and the respondents therefore may have been thinking of the one GTA/professor they had in college when responding. This study is also limited in that it was performed at a large southern research university with its own culture of instruction and curriculum that may not be present at the vast majority of other schools. Further, student demographics for each of the quantitative scenarios were not identical. As with many single-institution studies, the results cannot be generalized to all academic institutions; however, they can and should be used as the basis for additional investigations of GTA and professor instructional characteristics.

\section{Recommendations for GTA Professional Development}

The findings of this study suggest that undergraduates may have different perceptions of GTAs and professors with regard to several important instructional aspects. While additional investigations are certainly needed into why these factors are perceived differently by undergraduates, and whether these hold true at different institutions, these factors can be used in the meantime to help shape GTA professional development.

GTAs could be made aware of the results so they can better understand how undergraduates perceive them and come to know that most undergraduates do not understand the academic context of graduate students. GTA professional development should focus on keeping the positive aspects of GTA instructors (such as relatable, engaging, and approachable) while finding ways to decrease the perceived nervousness, uncertainty, and hesitancy of GTAs. For instance, universities can work to better prepare GTAs for the specific curriculum content they will be teaching. Marincovich et al. (1998) noted that GTA assigments are often made just prior to the semester, and suggested that if these assignments were known earlier, GTAs might be able to better prepare for the courses they will be teaching. Faculty often know their course assignments months in advance and invest considerable amounts of time preparing course materials and syllabi; GTAs should be given the same advance preparation time, if possible.

Shannon et al. (1998) and Luft et al. (2004) stated that GTAs should know more about curriculum delivery in general, and that providing professional development sessions in which GTAs are given background to deliver specific curricula may make them feel more confident and knowledgeable in the classroom. In addition to training in delivering specific curricula, GTAs should be encouraged to take time to reflect on their teaching for the purposes of self-evaluation; this will allow them to more quickly identify their personal teaching style, which should better promote student learning (Schussler et al., 2008).

GTAs could also be coached on behaviors that help them strike a balance between informal and relaxed and being strict and having high standards, because the former may be beneficial in terms of engaging students, but it can also be problematic in terms of authority and respect (Muzaka, 2009). Roach (1997) suggested that attire impacts student perception of the instructor; instructors dressed in professional attire may be afforded more classroom control and authority. Thus, GTAs can be informed of the importance of proper attire when instructing students.

This study identified positive and negative aspects of both GTA and professor instruction from the perspective of undergraduates. Often, where one instructor was weaker in an aspect, the other was strong. This suggests that another mechanism of professional development would be giving more opportunities for GTAs and professors to teach collaboratively, which could help each gain in aspects that are perceived as weaknesses by undergraduates. For instance, a professor working with a GTA on a course could help the GTA develop a better understanding of how to be more confident and organized about the curriculum and how to set higher standards. To achieve this, lecture and laboratory courses could be cotaught by professors and GTAs, versus separating those duties, or in cases in which this is not possible, GTAs could help coordinate the curriculum for a course they have been assigned to teach.

These recommendations for GTA professional development focus on maintaining as many of the positive aspects of GTA teaching as possible, while simultaneously finding ways to decrease the negative perceptions expressed by undergraduates. The overall goal of these new programs would be to increase GTA confidence in their teaching assignments and undergraduate perception of their teaching abilities, which should result in a better learning environment for everyone.

\section{CONCLUSIONS AND FUTURE DIRECTIONS}

There were several factors that undergraduates in this study perceived as being different between professors and GTAs; this study documented these differences and made suggestions for how to use this information to potentially improve teaching and learning at universities. Additional research, however, could further refine these results. For instance, exploration into why undergraduates perceive these differences may clarify why first-year students in this study had similar viewpoints compared with upper-level students with more exposure to different instructor types. Other research could study actual GTAs and professors to see whether the differences identified in this study hold true in practice or at other institutions. It would also be interesting to study undergraduate student perception of instructors who deviate from stereotypical instructor variables and how this impacts student perception of the instructor. For example, a professor who is nervous or a GTA who is unapproachable may be perceived more negatively, because they do not adhere to student expectations for that type of instructor. Future studies should also clarify the terms undergraduate students used 
in the study, for example, what exactly students mean when they say "strict" or "uncertain." Careful studies such as these will shed additional light on the complicated instructional relationships among undergraduates, GTAs, and professors, which may help each group to better understand how to maximize teaching and learning in undergraduate courses in the future.

\section{ACKNOWLEDGMENTS}

We thank the Division of Biology and Department of Ecology and Evolutionary Biology at the University of Tennessee for funding this project. We also thank the instructors and students who participated, as well as M. L. Niemiller for reviewing previous drafts of the manuscript.

\section{REFERENCES}

Anderson LE, Carta-Falsa J (2002). Factors that make faculty and students relationships effective. Coll Teach 50, 134-138.

Austin AE (2002). Preparing the next generation of faculty: graduate school as socialization to the academic career. J High Educ 73, 94-122.

Baldwin RG, Wawrzynski MR (2011). Contingent faculty as teachers: what we know; what we need to know. Am Behav Sci 55, 1485-1509.

Benjamin E (2002). How over reliance upon contingent appointments diminishes faculty involvement in student learning. Peer Review 5, 4-10.

Bolge RD (1995). Examination of Student Learning as a Function of Instructor Status (Full-Time vs. Part-Time) at Mercer County Community College. West Windsor, NJ: Mercer County Community College.

Bond-Robinson J, Rodriques RAB (2006). Catalyzing graduate teaching assistants' laboratory teaching through design. Res J Chem Educ $83,313-323$.

Bos RR, Zakrajsek DB, Wolf V, Stoll S (1980). Teaching assistant traits: their influence on student ratings. Improving Coll Univ Teach 28, 179-185.

Braxton JM, Lambert LM, Clark SC (1995). Anticipatory socialization of undergraduate college teaching norms by entering graduate teaching assistants. Res High Educ 36, 671-686.

Coll RK, Taylor N, Fisher DL (2002). An application of the Questionnaire on Teacher Interaction and college and university classroom environment inventory in a multicultural tertiary context. Res Sci Technol Educ 20, 165-183.

Corbin J, Strauss A (1990). Grounded theory research: procedures, canons, and evaluative criteria. Qual Sociol 13, 3-21.

Darby L (2005). Science students' perceptions of engaging pedagogy. Res Sci Educ 35, 425-445.

Dudley M (2009). Jumping out of an airplane: a TA's perspective on teaching effectiveness. Eastern Educ J 38, 1-10.

Flora BH (2007). Graduate assistants: students or staff, policy or practice? The current legal employment status of graduate assistants. J High Educ Pol Manag 29, 315-322.

Golde CM (1998). Beginning graduate school: explaining first-year doctoral attrition. In: The Experience of Being in Graduate School: An Exploration, New Directions for Higher Education, ed. M.S. Anderson, San Francisco: Jossey-Bass.

Golde CM, Dore TM (2001). At Cross Purposes: What the Experiences of Doctoral Students Reveal about Doctoral Education, Philadelphia, PA: Pew Charitable Trusts.
Huck S (2008). Reading Statistics and Research, Boston: Pearson Education.

Jaeger AJ (2008). Contingent faculty and student outcomes. Academe $94,42-43$.

Johnson IY (2011). Contingent instructors and student outcomes: an artifact or fact? Res High Educ 52, 761-785.

LeCompte MD (2000). Analyzing qualitative data. Theory Pract 39, 146-154.

Lowman J, Mathie V (1993). What should graduate teaching assistants know about teaching? Teach Psychol 20, 84-88.

Luft JA, Kurdziel JP, Roehrig GH, Turner J (2004). Growing a garden without water: graduate teaching assistants in introductory science laboratories at a doctoral/research university. J Res Sci Teach 41, 211-233.

Marincovich M, Prostko J, Stout F (eds.) (1998). The Professional Development of Graduate Teaching Assistants, Balton, MA: Anker Publishing.

Moos R (1979). Evaluating Educational Environments, San Francisco: Jossey-Bass.

Muzaka V (2009). The niche of graduate teaching assistant (GTAs): perceptions and reflections. Teach High Educ 14, 1-12.

Nyquist LM, Wulff DH, Austin AE, Sprague J, Fraser PK, Calcagno C, Woodford B (1999). On the road to becoming a professor: the graduate student experience. Change 31, 18-27.

O'Neal C, Wright M, Cook C, Perorazio T, Purkiss J (2007). The impact of teaching assistants on student retention in the sciences: lessons for TA training. J Coll Sci Teach 36, 24-29.

Park C (2002). Neither fish nor fowl? The perceived benefits and problems of using graduate teaching assistants (GTAs) to teach undergraduate students. High Educ Rev 35, 50-62.

Park C, Ramos M (2002). The donkey in the department? Insights into the graduate teaching assistant (GTA) experience in the UK. J Grad Educ 3, 47-53.

Roach K (1997). Effects of graduate teaching assistant attire on student learning, misbehaviors, and ratings of instruction. Commun Quart 45, 125-141.

Rushin JW, Saix JD, Lumsden A, Streubel DP, Summers G, Bernson C (1997). Graduate teaching assistant training: a basis for improvement of college biology teaching and faculty development? Am Biol Teach $59,86-90$.

Schussler E, Torres LE, Rybczynski S, Gerald GW, Monroe E, Sarkar P, Shahi D, Osman MA (2008). Transforming the teaching of science graduate students through reflection. J Coll Sci Teach 38, 32-36.

Shannon DM, Twale DJ, Moore MS (1998). TA teaching effectiveness: the impact of training and teaching experience. J High Educ 69, 440466.

Sundberg MD, Armstrong JE, Wischusen EW (2005). A reappraisal of the status of introductory biology laboratory education in U.S. colleges and universities. Am Biol Teach 67, 525-529.

Treagust DF, Fraser BJ (1986). Validation and application of the college and university classroom environment inventory (CUCEI). Paper presented at the Annual Meeting of the American Educational Research Association, San Francisco, CA, April 16-20.

Umbach PD (2007). How effective are they? Exploring the impact of contingent faculty on undergraduate education. Rev High Educ 30, 91-123.

Umbach PD, Wawrzynski MR (2005). Faculty do matter: the role of college faculty in student learning and engagement. Res High Educ $46,153-184$. 